\title{
Experimental Investigation of Reactive Extraction of Levulinic Acid from Aqueous Solutions
}

\author{
A. Kumar, D. Z. Shende, and K. L. Wasewar* \\ Department of Chemical Engineering, \\ Visvesvaraya National Institute of Technology (VNIT), \\ Nagpur 440010, India
}

doi: https://doi.org/10.15255/CABEQ.2021.2031

Original scientific paper

Received: April 15, 2021

Accepted: November 23, 2021

The separation of levulinic acid from aqueous solutions is costly and non-ecofriendly in many cases. The major concerns are the low concentration of levulinic acid in fermentation broths and industrial downstreams. In this study, reactive extraction of levulinic acid from aqueous phase is proposed and its efficacy was investigated. Various extractants viz. tri- $n$-butyl phosphate, trioctylamine, and trioctylmethylammonium chloride along with $i$-octanol as a diluent were used. The extent of separation was investigated and various performance parameters like extraction efficiency, distribution coefficient, equilibrium complexation constant, and loading ratio were estimated. The number of transfer units, diffusivity, and mass transfer considerations were also discussed in the reactive separation system. Finally, the conceptual method was provided for the separation of levulinic acid using efficient reactive separation.

Keywords:

levulinic acid, reactive extraction, aqueous solution, diffusivity, number of theoretical stages

\section{Introduction}

Levulinic acid (LA) is a colorless acid, containing ketone and carboxylic acid group. It is soluble in ethanol, diethyl ether, and water. ${ }^{1}$ LA can be considered a promising building block chemical in the field of biofuels, pharmaceuticals, food, agriculture, cosmetics, polymers, and chemical solvents. ${ }^{2-7}$ The demand for LA and its derivatives such as succinic acid, valerolactone, 2-methyltetrahydrofuran, $\alpha$-methylene- $\gamma$-valerolactone, aminolevulinic acid, and hydroxyvaleric acid is increasing continuously. LA finds its major application in the agricultural and cosmetics industries. Thus, levulinic acid is effective and safe for application in personal care and cosmetic products because it controls the bacterial growth in cosmetic products to increase their shelf life. ${ }^{8}$ Sodium levulinate, a derivative of levulinic acid, is commonly used for skin treatment. ${ }^{9}$ According to the market report, GFBiochemicals Ltd. is the top company for the production of LA in the world. ${ }^{10}$ The other major manufacturing industries are Hebei Yanuo, Heroy Chemical Industry, Zibo Changlin Chemical, Hefei TNJ Chemical, Guannan East Chemical, Langfang Triple Well Chemicals, Zibo Shuangyu, and Lang Fang Hawk. According to the Department of Energy of United States, LA is ranked among the top twelve bio-based chemicals of the future. ${ }^{11-13}$ As per the New York report, mar-

"Corresponding author: E-mail address: klwasewar@che.vnit.ac.in, k_wasewar@rediffmail.com ket of LA is likely to touch USD 61.2 million by 2027. ${ }^{14}$

LA can be produced from agricultural waste biomass as it contains glucose, fructose, and xylose. Researchers have used waste biomass like wheat straw, rice husk, sugarcane bagasse, rice straw, corn stover, and quercus-mongolica biomass for the production of LA. ${ }^{15-22}$ At industrial scale, LA is produced directly from biomass through the hydrolysis process. Therein, the biomass is heated to around $433.15 \mathrm{~K}$, and the acidic medium attacks cellulosic glycosidic bonds to produce glucose monomers. Glucose then undergoes acid catalyzed intermolecular dehydration and is subsequently converted into 5-hydroxymethylfurfural (5-HMF). Further, 5-HMF is rehydrated and converted into levulinic acid. ${ }^{23,24}$ LA is commonly found in low concentrations $(<10 \%)$ in fermentation broths and industrial downstreams. ${ }^{25}$ Various methods are present for separation of carboxylic acids from aqueous solutions like distillation, adsorption, evaporation, liquid-liquid extraction, chromatography, ion exchange, reverse-osmosis, absorption, etc. ${ }^{26}$ All of them are expensive and time-consuming. On the other hand, reactive extraction is a cheap, easy, and sustainable alternative method. ${ }^{27}$ It has potential for the recuperation of value-added acids from fermentation broths and wastewater. ${ }^{28}$ In this method, the molecules of the reactive component dissolved in the suitable solvent react with solute at the interface to form the reversible reaction complex, and the trans- 
fer of acid molecules takes place by the solubilization and diffusion mechanisms in the organic phase. Reactive extraction is one of the process intensification methods wherein the separation is enhanced because of reaction. Researchers have successfully employed reactive extraction for recovering value-added chemicals like formic, acetic, picolinic, levulinic, citric, itaconic, acrylic, propionic, pyruvic, malic, succinic, and phenylacetic acid from the aqueous phase..$^{29-38}$

In the present study, the separation efficiency of LA was investigated using various extractants like an organophosphorus compound (tri-n-butyl phosphate), tertiary amine (trioctylamine), and a quaternary ammonium salt (trioctylmethylammonium chloride / Aliquat 336). The experimental results are described in terms of performance parameters like distribution coefficient $\left(K_{\mathrm{D}}\right)$, loading ratio $(Z)$, equilibrium complexation constant $\left(K_{\mathrm{E}}\right)$, and extraction efficiency $(\eta)$. Further, the design considerations were studied by predicting the number of transfer units, diffusivity, and equilibrium constants using various mathematical approaches.

\section{Materials and methods}

\section{Chemicals}

Levulinic acid ( $>98 \%$, Sigma-Aldrich), trioctylamine ( $>95 \%$, Spectrochem Pvt. Ltd.), tri- $n$-butyl phosphate ( $>99 \%$, Spectrochem Pvt. Ltd.), trioctylmethylammonium chloride $(>88 \%$, Loba Chemie Pvt. Ltd.), and $i$-octanol (2-ethylhexan-1-ol, $>99 \%$, Loba Chemie Pvt. Ltd.) were purchased. $\mathrm{NaOH}$ was supplied by Merck Specialities Pvt. Ltd. The phenolphthalein indicator was supplied by Fisher Scientific (India) and used for acid-base titrations at $\mathrm{pH} 8-10$. Oxalic acid was supplied by SD Fine Chem Ltd., and used for the standardization of $\mathrm{NaOH}$ solutions. Model solutions of aqueous LA were prepared with distilled water. A fresh solution of sodium hydroxide was prepared every time and standardized with oxalic acid solution. All the chemicals were used with no further treatment and their properties are described in Table 1.

\section{Experimental method}

To perform reactive extraction experiments, $0.441 \mathrm{~mol} \mathrm{~kg}^{-1}$ concentration of LA was dissolved in distilled water to prepare an aqueous solution. Selected for this study was a $0.441 \mathrm{~mol} \mathrm{~kg}^{-1}$ concentration of LA, based on our previous study. ${ }^{30}$ Various extractants: tri-i-butyl phosphate (TBP), trioctylamine (TOA), and trioctylmethylammonium chloride (Aliquat 336) were diluted in $i$-octanol (20-100 vol\%) for preparation of the organic phase. The volumetric ratio of $1: 1$ of both solutions was mixed in a conical flask and shaken in incubator (Model: S-24BL, Made: REMI India) with $200 \mathrm{rpm}$ for $4 \mathrm{~h}$ at $298.15 \mathrm{~K}$. The duration of $4 \mathrm{~h}$ for shaking was considered as sufficient to achieve the equilibrium between the phases. ${ }^{29}$ After shaking, samples were centrifuged (4000 rpm for $5 \mathrm{~min}$ ) for phase settling. The aqueous phase $\mathrm{pH}$ was measured by a $\mathrm{pH}$ meter (IKA ${ }^{\circledR}$ EDS-D6) before and after the phase equilibration experiment. The acid phase solution was titrated by $0.1 \mathrm{~N} \mathrm{NaOH}$ solutions with the phenolphthalein indicator to determine LA concentration in the aqueous phase, and organic phase concentration was calculated from the material balance. The experimental process diagram is shown in Fig. 1.

\section{Experimental uncertainty}

All experiments were repeated and analyzed three times for the uncertainty analysis and found to fall within $\pm 2 \%$ interval with an uncertainty analysis error below $\pm 5 \%$. The following equation can be used to obtain experimental uncertainty $X$ within \pm 0.001 . $^{39}$

$$
\mu(X)=\left[\frac{\sum_{i=1}^{N}\left(X_{i}-\bar{X}\right)^{2}}{(N-1)}\right]^{1 / 2}
$$

where $\bar{X}$, and $N$ are the mean values of the experiment and the number of performed experiments.

Table 1 - List of various chemicals and solvents used in the experiments

\begin{tabular}{l|c|c|c|c}
\hline \multicolumn{1}{c|}{ Reagent name } & CAS number & $\begin{array}{c}\text { Purity } \\
(\text { mass fraction })\end{array}$ & $\begin{array}{c}\text { Viscosity } \\
(\text { Pa s) }\end{array}$ & $\begin{array}{c}\text { Density } \\
\left(\mathrm{kg} \mathrm{m} \mathrm{m}^{-3}\right.\end{array}$ \\
\hline Levulinic acid & $123-76-2$ & 0.98 & - & 1.140 \\
$i$-Octanol & $111-87-5$ & 0.99 & $10.6 \cdot 10^{-3}$ & 833 \\
Trioctylamine (TOA) & $1116-76-3$ & 0.95 & $7.862 \cdot 10^{-3}$ & 809 \\
Tri- $n$-butylphosphate (TBP) & $126-73-8$ & 0.99 & $3.39 \cdot 10^{-3}$ & 975 \\
Trioctylmethylammonium chloride (Aliquat 336) & $5137-55-3$ & 0.88 & 1.45 & 884 \\
Sodium hydroxide & $1310-73-2$ & - & - & 213 \\
Phenolphthalein & $77-09-8$ & 1.00 & - & 190 \\
\hline
\end{tabular}




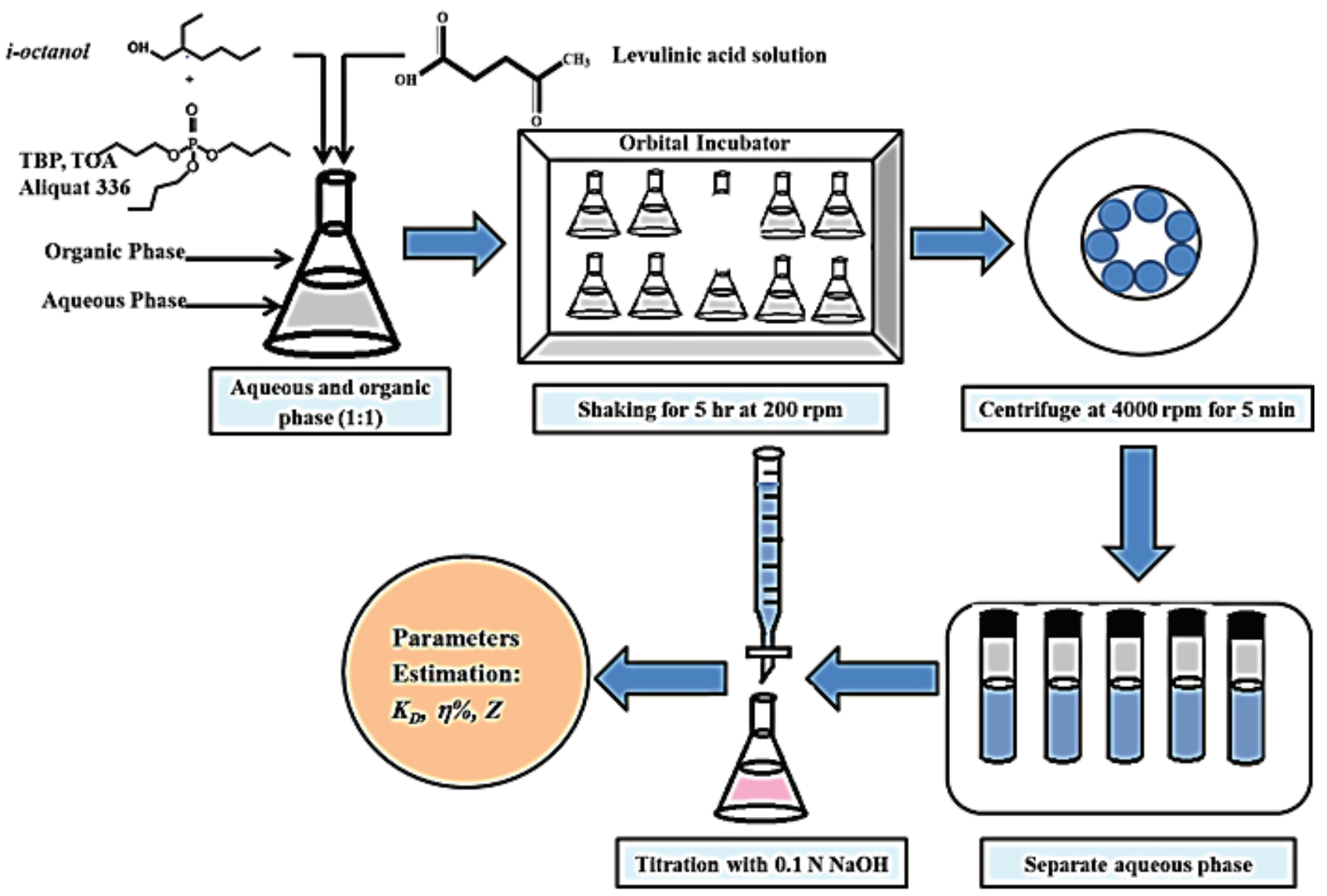

Fig. 1 - Block diagram of the experimental procedure for the separation of levulinic acid

\section{Results and discussion}

Various extractants like tri- $n$-butyl phosphate, trioctylamine, and trioctylmethylammonium chloride with $i$-octanol were used to form the organic phase for the extraction of LA from the aqueous phase of the $0.441 \mathrm{~mol} \mathrm{~kg}^{-1}$ LA concentration. According to the results, pure $i$-octanol cannot be considered as a good option because it provides low extraction efficiency of $17 \%$ and distribution coefficient of 0.211 . Generally, the separation efficiency depends on the physical properties of extractants like solubility, molecular weight, polarity, viscosity, dielectric constant, etc. ${ }^{40}$ To improve the physical properties, $i$-octanol was used as solvent for various extractants like TBP, TOA, and Aliquat 336. The $\mathrm{pH}$ range of 3.21-3.59 was observed in the aqueous phase before the equilibrium experiment with TBP, TOA, and Aliquat 336; particular values are listed in Table 2.
Table 2 illustrates the maximum distribution coefficient of 2.173 with $100 \%$ TBP, and 2.938 with $100 \%$ Aliquat 336. However, the maximum distribution coefficient of 4.011 was achieved with $40 \%$ TOA, and afterwards, $K_{\mathrm{D}}$ was found to decrease continuously with the increase of TOA concentration. TBP (organophosphorus compound), Aliquat 336 (quaternary ammonium salt), and $i$-octanol exhibit relatively high viscosity $\left(3.39 \cdot 10^{-3}\right.$ $\mathrm{Pa} \mathrm{s}, 1.45 \mathrm{~Pa} \mathrm{~s}$, and $10.6 \cdot 10^{-3} \mathrm{~Pa} \mathrm{~s}$ ), which may pose the resistance for the transfer of acid molecules from aqueous phase to organic phase and decrease mass transfer rate. To accelerate the extractive reaction, a low-viscosity diluent can be used with TBP and Aliquat 336 instead of $i$-octanol. However, this is the kinetic effect and thus it should not affect the distribution coefficient as a thermodynamic property if true equilibrium is reached. Thus, the increase in $K_{\mathrm{D}}$ with decreasing the concentration of highly viscous $i$-octanol cannot be attributed to the increas-

The distribution coefficient can be defined as: ${ }^{41}$

$$
K_{\mathrm{D}}=\frac{\text { conc. of LA in organic phase } \cdot \text { volume of organic phase }}{\text { conc. of LA in aqueous phase } \cdot \text { volume of aqueous phase }} \quad K_{\mathrm{D}}=\frac{[\mathrm{LA}]_{\mathrm{O}} V_{\mathrm{O}}}{[\mathrm{LA}]_{\mathrm{W}} V_{\mathrm{W}}}
$$

where $[\mathrm{LA}]_{\mathrm{W}}$ and $[\mathrm{LA}]_{\mathrm{O}}$ are the concentrations of LA in the aqueous phase and organic phase, respectively, and $V_{\mathrm{O}} / V_{\mathrm{w}}$ is the volume ratio of organic to aqueous phase. 
Table 2 -Various parameters of reactive separation of levulinic acid of $0.441 \mathrm{~mol} \mathrm{~kg}^{-1}$ concentration from aqueous solution using TOA, TBP, and Aliquat 336 with i-octanol at $298.15 \pm K^{*}$

\begin{tabular}{|c|c|c|c|c|c|c|c|c|c|}
\hline $\begin{array}{c}\text { Extractant } \\
{[\mathrm{E}]}\end{array}$ & $\begin{array}{c}{[\mathrm{E}]_{\mathrm{org}}} \\
(\operatorname{vol} \%)\end{array}$ & $\begin{array}{c}{[\mathrm{LA}]_{\mathrm{W}}} \\
\left(\mathrm{mol} \mathrm{kg}^{-1}\right)\end{array}$ & $\begin{array}{c}{[\mathrm{LA}]_{\mathrm{O}}} \\
\left.(\mathrm{mol} \mathrm{kg})^{-1}\right)\end{array}$ & $K_{\mathrm{D}}$ & $\eta \%$ & $Z$ & $\begin{array}{l}\mathrm{pH} \text { of } \\
\text { aqueous } \\
\text { phase }\end{array}$ & $K_{\mathrm{E}}$ & $m$ \\
\hline \multirow[t]{5}{*}{ TBP } & 20 & 0.344 & 0.097 & 0.282 & 22.00 & 0.130 & 3.59 & 0.114 & 0.670 \\
\hline & 40 & 0.29 & 0.151 & 0.521 & 34.24 & 0.101 & 3.47 & & \\
\hline & 60 & 0.264 & 0.177 & 0.670 & 40.14 & 0.079 & 3.41 & & \\
\hline & 80 & 0.209 & 0.232 & 1.110 & 52.61 & 0.078 & 3.36 & & \\
\hline & 100 & 0.139 & 0.302 & 2.173 & 68.48 & 0.081 & 3.29 & & \\
\hline \multirow[t]{5}{*}{ Aliquat 336} & 20 & 0.339 & 0.102 & 0.301 & 23.13 & 0.234 & 3.52 & 0.180 & 0.688 \\
\hline & 40 & 0.271 & 0.17 & 0.627 & 38.55 & 0.195 & 3.48 & & \\
\hline & 60 & 0.24 & 0.201 & 0.838 & 45.58 & 0.154 & 3.45 & & \\
\hline & 80 & 0.189 & 0.252 & 1.333 & 57.14 & 0.144 & 3.39 & & \\
\hline & 100 & 0.112 & 0.329 & 2.938 & 74.60 & 0.151 & 3.35 & & \\
\hline \multirow[t]{5}{*}{ TOA } & 20 & 0.118 & 0.323 & 2.737 & 73.24 & 0.600 & 3.55 & 0.388 & 0.490 \\
\hline & 40 & 0.088 & 0.353 & 4.011 & 80.05 & 0.328 & 3.49 & & \\
\hline & 60 & 0.101 & 0.34 & 3.366 & 77.10 & 0.211 & 3.43 & & \\
\hline & 80 & 0.175 & 0.266 & 1.520 & 60.32 & 0.124 & 3.33 & & \\
\hline & 100 & 0.213 & 0.228 & 1.070 & 51.70 & 0.085 & 3.21 & & \\
\hline
\end{tabular}

"Standard uncertainties $(\mu)$ are $\mu(C)= \pm 0.001 \mathrm{~mol} \mathrm{~kg}^{-1}, \mu(T)= \pm 1 \mathrm{~K}$.

ing transfer rate. The behavior of TOA as an extractant is significantly different in comparison to TBP and Aliquat 336. It is based on the acid-amine neutralization reaction coupled with the solvation of the amine-acid complex based on dipole-dipole interaction. Thus, amines are known to form $2: 1$ and 3:1 complexes with acids in the organic phase. ${ }^{42}$

Fig. 2 shows the concentration of LA transferred to the organic phase at equilibrium using TBP, TOA, and Aliquat 336 with $i$-octanol. With increasing volume (20-100 \%) of TBP and Aliquat 336 , the concentration of organic phase LA also increases. In the case of TOA after $40 \%$, the concentration of organic phase LA continuously decreases. The distribution coefficient was found in the range of $0.282-2.170,1.070-4.011$, and $0.301-2.938$ using TBP, TOA, and Aliquat 336 in $i$-octanol, respec- tively. The strong amine and acid complexes form in the organic phase and provide higher distribution coefficient. ${ }^{43}$ Thus, TOA was found to be the best reactive extractant among the extractants studied here in $i$-octanol solutions for the separation of LA.

The extraction efficiency $(\eta)$ can be calculated using the following equation:

$$
\eta \%=\left(\frac{K_{\mathrm{D}}}{1+K_{\mathrm{D}}}\right) \cdot 100
$$

The highest extraction efficiency of $80.05 \%$ was observed with $40 \%$ TOA in $i$-octanol as compared to the TBP and Aliquat 336 (Fig. 3).

The loading ratio $(Z)$ depends on the strength of the acid-base interaction and the stoichiometry of the overall extraction equilibrium..$^{44-46}$

The $Z$ value was calculated using the following equation:

$$
\text { Loading ratio }(Z)=\frac{\text { Concentration of levulinic acid in organic phase }}{\text { Initial concentration of extractant in organic phase }}=\frac{[\mathrm{LA}]_{\mathrm{org}}}{[\mathrm{E}]_{\mathrm{org}}}
$$




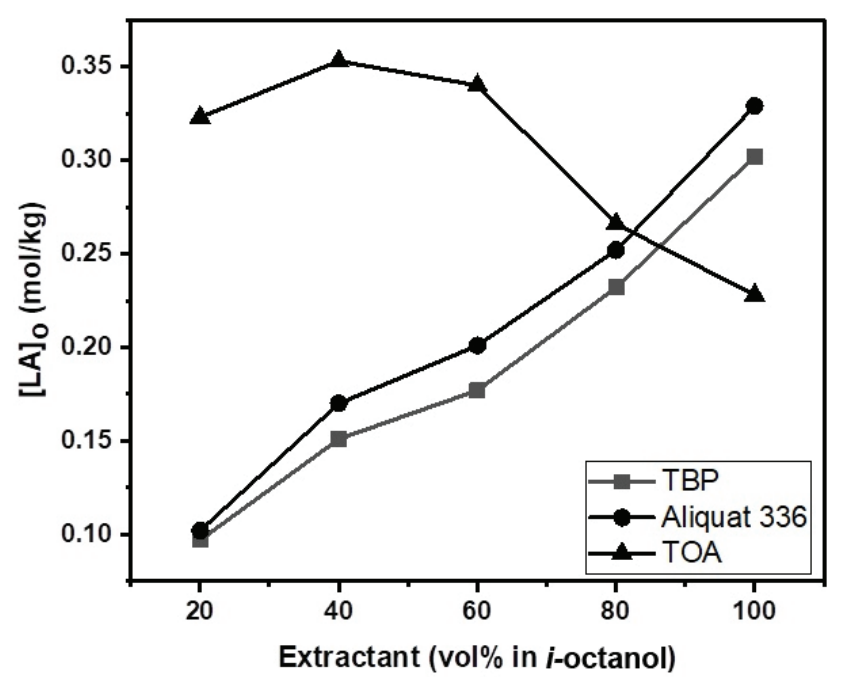

Fig. 2 - Equilibrium concentration of levulinic acid (LA) transferred in organic phase using TBP, Aliquat 336, and TOA with $i$-octanol using initial acid concentration of $0.441 \mathrm{~mol} \mathrm{~kg}^{-1}$

The loading ratio decreases with the increase of extractant concentration in the organic phase. Table 2 shows the loading ratio values lower than 0.5 for the cases of TBP and Aliquat 336 in $i$-octanol. Thus, it seems that there is a possibility for forming $1: 1$ acid-extractant complexes only. In the case of TOA, a loading factor higher than 0.5 was found in one case, and hence the acid-extractant complexes of $1: 1$ and $2: 1$ could be formed in the organic phase. ${ }^{47}$ The loading ratio decreases with TOA concentration because the solvent becomes a less favorable solvating medium and because of the abundance of

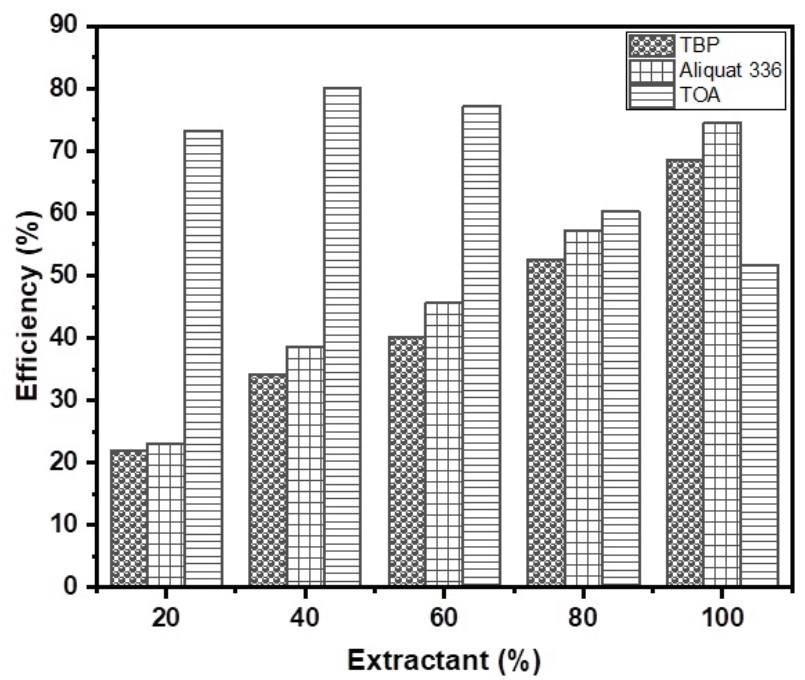

Fig. 3 - Effect of the type of extractant and its volume \% in the mixtures with $i$-octanol diluent on the extraction efficiency of levulinic acid

TOA molecules. ${ }^{48}$ The probable reaction mechanism of reactive separation of LA using extractant is displayed in Fig. 4.

The acid-extractant complex formation in the organic phase is as follows:

$$
\begin{gathered}
\mathrm{LA}+m \mathrm{E}_{\text {org }} \rightleftharpoons \mathrm{LA} .(\mathrm{E})_{\mathrm{s}, \text { org }} \\
K_{\mathrm{E}}=\frac{[\mathrm{LA}][\mathrm{E}]_{\text {org }}^{m}}{[\mathrm{LA} \cdot \mathrm{E}]_{\mathrm{org}}}
\end{gathered}
$$

where $m$ is the solvation number, and $\mathrm{E}_{\text {org }}$ is the extractant in the organic phase.

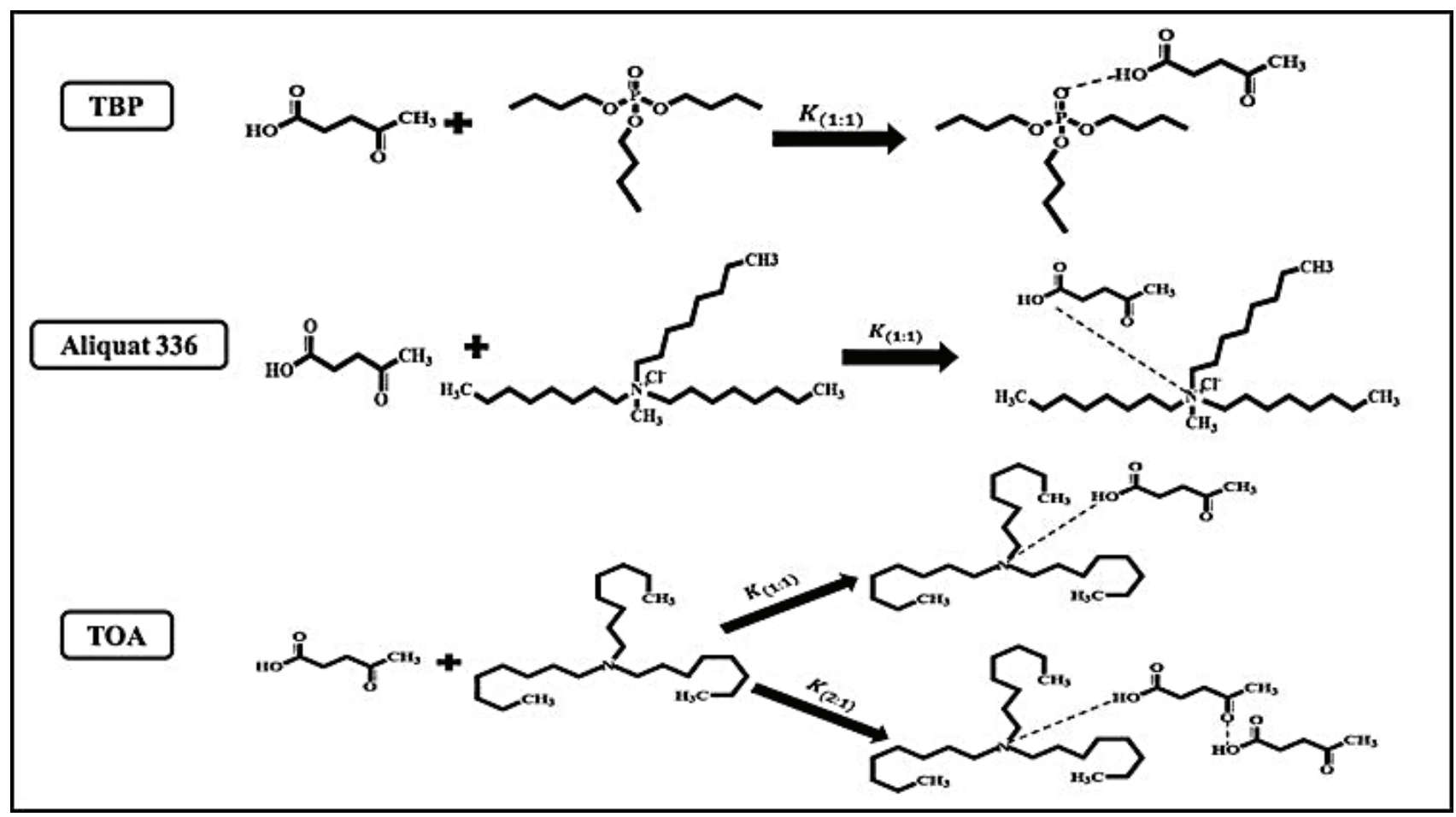

Fig. 4 -Complex formation (a) LA with TBP in the organic phase, (b) LA with Aliquat 336, (c) LA with TOA 
Aqueous phase acid ionization can be written as:

$$
\begin{aligned}
\mathrm{LA} & \rightleftharpoons \mathrm{H}^{+}+\mathrm{LA}^{-} \\
K_{\mathrm{LA}} & =\frac{\left[\mathrm{H}^{+}\right]\left[\mathrm{LA}^{-}\right]}{[\mathrm{LA}]}
\end{aligned}
$$

where, $K_{\mathrm{LA}}$ is the dissociation constant.

The distribution coefficient can be expressed as:

$$
K_{\mathrm{D}}=\frac{[\mathrm{LA}]_{\mathrm{org}}}{[\mathrm{LA}]_{\mathrm{aq}}}=\frac{\left[\mathrm{LA} \cdot \mathrm{E}_{\mathrm{s}}\right]_{\mathrm{org}}}{[\mathrm{LA}]+\left[\mathrm{LA}^{-}\right]}
$$

where $\left[\mathrm{L} . \mathrm{AE}_{\mathrm{s}}\right]_{\mathrm{org}}$ denotes the concentration of the complex between acid and extractant in the organic phase.

Equations (6), (7), and (8) can be combined and expressed as:

$$
\begin{gathered}
K_{\mathrm{D}}=\frac{K_{\mathrm{E}}[\mathrm{LA}][\mathrm{E}]_{\mathrm{org}}^{m}}{[\mathrm{LA}]+K_{\mathrm{LA}}[\mathrm{LA}] /\left[\mathrm{H}^{+}\right]} \\
K_{\mathrm{D}}=\frac{K_{\mathrm{E}}[\mathrm{E}]_{\mathrm{org}}^{m}}{1+K_{\mathrm{LA}} /\left[\mathrm{H}^{+}\right]}
\end{gathered}
$$

Equation (10) can be rewritten as:

$$
\log K_{\mathrm{D}}+\log \left(1+K_{\mathrm{LA}} /\left[\mathrm{H}^{+}\right]\right)=\log K_{\mathrm{E}}+m \log [\mathrm{E}]_{\mathrm{org}}
$$

The values of $m$ and $K_{\mathrm{E}}$ were calculated using the plot between $\log K_{\mathrm{D}}+\log \left(1+K_{\mathrm{LA}} /\left[\mathrm{H}^{+}\right]\right)$vs $\log$ $[E]_{\text {org }}$ which should yield a straight line with the slope of $m$ and an intercept of $\log K_{\mathrm{E}}$ (Fig. 5). (Please note that $\left[\mathrm{H}^{+}\right]$can be calculated from $\mathrm{pH}$ value in equilibrium.) In case of TOA, the straight line gave the negative slope because the extraction efficiency continuously decreased with increasing TOA concentration above $40 \%$. Thus, only the part of concentration range giving the physically meaningful positive slope was taken into account. The $K_{\mathrm{E}}$ value is related to the extraction of acid; $K_{\mathrm{E}}<1$ indicates the low extraction efficiency, and $K_{\mathrm{E}}>1$ defines the good extraction efficiency of the acid. ${ }^{49}$ The values of $K_{\mathrm{E}}$ and $m$ were found as 0.114 and 0.670 for TBP, 0.180 and 0.688 for Aliquat 336, and 0.388 and 0.490 for TOA. The low values $(0.49$ to 0.688 ) for the used extractant confirmed that 1.52.0 molecules of LA were attached with one molecule of reactive extractant (TBP, Aliquat 336, and TOA) to form the acid-extractant complex.

The solubility of TOA in water is very low (0.039 $\left.\mathrm{mg} \mathrm{L}^{-1}\right) ;{ }^{50}$ TOA provided a higher extraction efficiency and distribution coefficient as compared to TBP and Aliquat 336. Amines, and in particular tertiary amines, are stable in contact with water during reactive extraction and they are capable of complexing more than one acid molecule at a time (e.g., 2:1 complex), ${ }^{51}$ which depends on the concen-
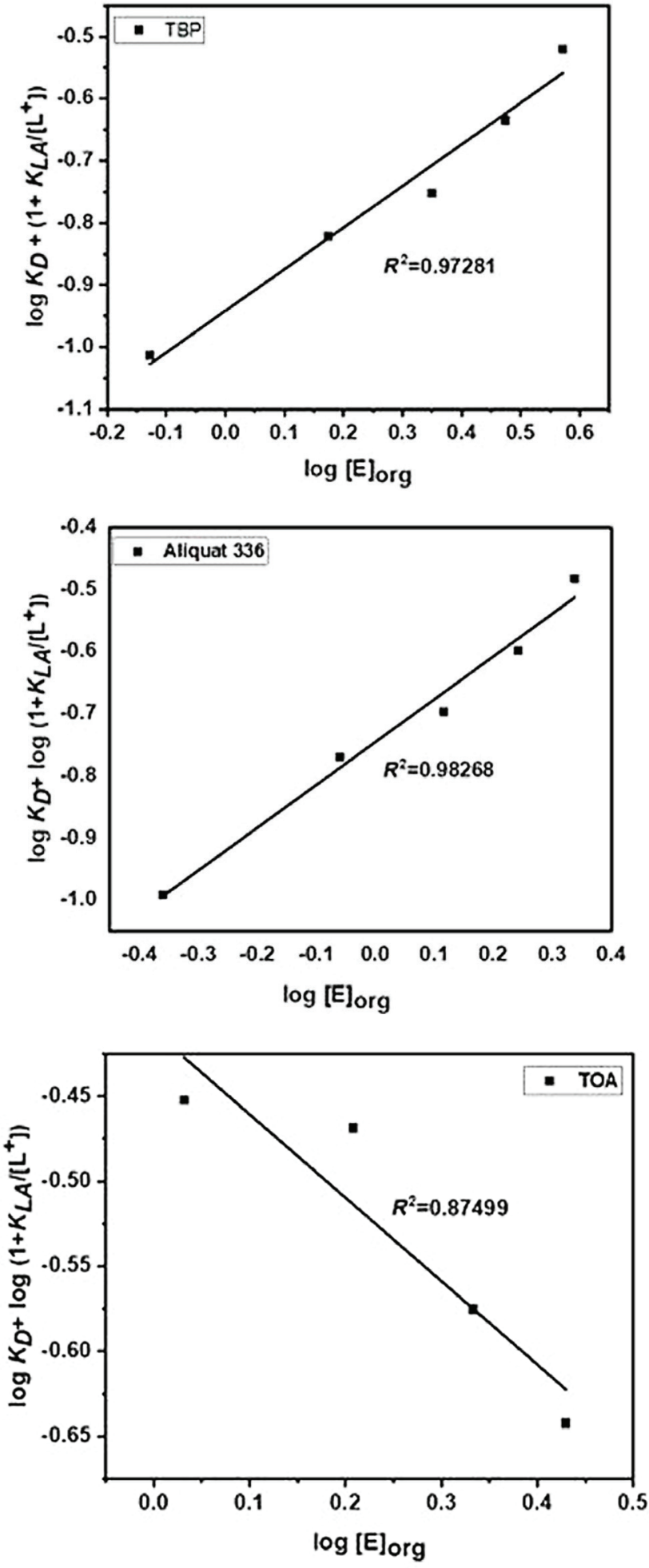

Fig. $5-K E$ values evaluated for the extraction of levulinic acid using TBP, Aliquat 336, and TOA

tration of TOA in diluent and acid in the aqueous phase. Therefore, TOA can be considered as a good reactive extractant for the separation of LA as compared to TBP and Aliquat 336.

For a better understanding of the reactive extraction of acids, it is essential to estimate the interphase diffusion coefficient as it relates to the physi- 
cochemical properties of the diluents. It is mainly dependent on pressure and temperature. The interphase diffusion coefficient indicates the mass transfer of acid molecules within organic phase. For calculating the interphase diffusion coefficient in liquid systems various equations can be used. ${ }^{52}$ Those equations correlate various parameters, such as $M$, molecular weight of solvent; $\mu$, solvent viscosity; $T$, temperature; $v$, molar volume of solute; $v_{\mathrm{S}}$, molar volume of solvent, etc..$^{53}$

The interphase diffusion coefficient $\left(D_{\text {LA-S }}\right)$ of LA in organic solvents like $i$-octanol, tri- $n$-butyl phosphate, trioctylamine, and trioctylmethylammonium chloride at $298.15 \pm 1 \mathrm{~K}$ can be estimated using the following equations.

Wilke-Chang equation is expressed as: ${ }^{54}$

$$
D_{\mathrm{LA}-\mathrm{S}}=7.4 \cdot 10^{-8} \frac{\sqrt{\mathrm{x} M} T}{\mu v_{\mathrm{LA}}^{0.6}}
$$

where $\mathrm{x}$ is the association parameter $(\mathrm{x}=1$ for non-associated solvents and $\mathrm{x}=2.6$ for water). Viscosity $\mu$ is entered in $\mathrm{cP}(1 \mathrm{cP}=0.001 \mathrm{~Pa} \mathrm{~s}), M$ is entered in $\mathrm{g} \mathrm{mol}^{-1}, T$ is entered in $\mathrm{K}$, and $v_{\mathrm{LA}}$ is molar volume of levulinic acid entered in $\mathrm{cm}^{3} \mathrm{~mol}^{-1}$.

Reddy-Doraiswamy equation can be written as follows to determine the interphase diffusion coefficient: ${ }^{53}$

$$
D_{\mathrm{LA}-\mathrm{S}}=\frac{(\bar{a}) M^{0.5} T}{\mu\left(v_{\mathrm{LA}} v_{\mathrm{S}}\right)^{1 / 3}}
$$

All the values are entered with the units defined as before; $v_{\mathrm{s}}$ is molar volume of solvent entered in $\mathrm{cm}^{3} \mathrm{~mol}^{-1}$.. $\bar{a}$ is the the constant which depends on the ratio $v_{\mathrm{LA}} / v_{\mathrm{s}}\left(\bar{a}=10 \cdot 10^{-8}\right.$ for $v_{\mathrm{LA}} / v_{\mathrm{S}} \leq$ 1.5 , and $\bar{a}=8.5 \cdot 10^{-8}$ for $\left.v_{\mathrm{LA}} / v_{\mathrm{S}}>1.5\right)$.

With all the values entered with the units defined as before, Scheibel equation is expressed as: ${ }^{55}$

$$
D_{\mathrm{LA}-\mathrm{S}}=\frac{8.2 \cdot 10^{-8} T}{\mu\left(v_{\mathrm{LA}}\right)^{1 / 3}}\left[1+\left(\frac{3 v_{\mathrm{S}}}{v_{\mathrm{LA}}}\right)^{2 / 3}\right]
$$

Similarly, Lusis-Ratcliff equation can be written as: ${ }^{.6}$

$$
D_{\mathrm{LA}-\mathrm{S}}=\frac{8.2 \cdot 10^{-8} T}{\mu\left(v_{\mathrm{S}}\right)^{1 / 3}}\left[1.40\left(\frac{v_{\mathrm{S}}}{v_{\mathrm{LA}}}\right)^{1 / 3}+\left(\frac{v_{\mathrm{S}}}{v_{\mathrm{LA}}}\right)\right]
$$

The interphase diffusion coefficient was calculated at various volume \% of extractants and solvents. Molar volumes and viscosities of organic phase (solvent + extractant) were averaged based on their volume fraction. The results for pure $i$-octanol provide the diffusion coefficients in the range of $1.03 \cdot 10^{-7}$ to $1.48 \cdot 10^{-6} \mathrm{~cm}^{2} \mathrm{~s}^{-1}$, depending on the equation (Table 3). The Wilke-Chang and Reddy-Doraiswamy equations estimate higher values of interphase diffusion coefficient in TBP, TOA, and Aliquat 336 as compared to Scheibel and Lusis-Ratcliff equations. The lowest interphase diffusion coefficient was estimated in Aliquat 336 because of its

\begin{tabular}{|c|c|c|c|c|c|}
\hline Solvents & \begin{tabular}{|c|} 
Organic phase \\
(Volume \%)
\end{tabular} & $\begin{array}{c}D_{\text {LA-S }} \text { [Wilke-Chang } \\
\text { equation] }\left(\mathrm{cm}^{2} \mathrm{~s}^{-1}\right)\end{array}$ & $\begin{array}{c}D_{\text {LA-S }}[\text { Reddy-Doraiswamy } \\
\text { equation] }\left(\mathrm{cm}^{2} \mathrm{~s}^{-1}\right)\end{array}$ & $\begin{array}{c}D_{\text {LA-S }}[\text { Scheibel } \\
\text { equation }]\left(\mathrm{cm}^{2} \mathrm{~s}^{-1}\right)\end{array}$ & $\begin{array}{l}\mathrm{D}_{\text {LA-s }} \text { [Lusis-Ratcliff } \\
\text { equation] }\left(\mathrm{cm}^{2} \mathrm{~s}^{-1}\right)\end{array}$ \\
\hline$i$-octanol & 100 & $1.480 \cdot 10^{-6}$ & $1.273 \cdot 10^{-6}$ & $5.514 \cdot 10^{-7}$ & $1.035 \cdot 10^{-7}$ \\
\hline $\mathrm{TBP}+i$-octanol & $(20+80)$ & $1.886 \cdot 10^{-6}$ & $1.620 \cdot 10^{-6}$ & $6.383 \cdot 10^{-7}$ & $1.198 \cdot 10^{-7}$ \\
\hline $\mathrm{TBP}+i$-octanol & $(40+60)$ & $2.941 \cdot 10^{-6}$ & $2.527 \cdot 10^{-6}$ & $9.191 \cdot 10^{-7}$ & $1.725 \cdot 10^{-7}$ \\
\hline $\mathrm{TBP}+i$-octanol & $(60+40)$ & $3.194 \cdot 10^{-6}$ & $2.744 \cdot 10^{-6}$ & $9.317 \cdot 10^{-7}$ & $1.748 \cdot 10^{-7}$ \\
\hline $\mathrm{TBP}+i$-octanol & $(80+20)$ & $4.405 \cdot 10^{-6}$ & $3.785 \cdot 10^{-6}$ & $1.209 \cdot 10^{-6}$ & $2.270 \cdot 10^{-7}$ \\
\hline TBP & $(100)$ & $6.627 \cdot 10^{-6}$ & $5.694 \cdot 10^{-6}$ & $1.724 \cdot 10^{-6}$ & $3.236 \cdot 10^{-7}$ \\
\hline TOA $+i$-octanol & $(20+80)$ & $1.811 \cdot 10^{-6}$ & $1.556 \cdot 10^{-6}$ & $5.814 \cdot 10^{-7}$ & $1.091 \cdot 10^{-7}$ \\
\hline TOA $+i$-octanol & $(40+60)$ & $2.146 \cdot 10^{-6}$ & $1.844 \cdot 10^{-6}$ & $6.149 \cdot 10^{-7}$ & $1.154 \cdot 10^{-7}$ \\
\hline TOA $+i$-octanol & $(60+40)$ & $2.498 \cdot 10^{-6}$ & $2.147 \cdot 10^{-6}$ & $6.525 \cdot 10^{-7}$ & $1.225 \cdot 10^{-7}$ \\
\hline TOA $+i$-octanol & $(80+20)$ & $2.877 \cdot 10^{-6}$ & $2.472 \cdot 10^{-6}$ & $6.950 \cdot 10^{-7}$ & $1.304 \cdot 10^{-7}$ \\
\hline TOA & $(100)$ & $3.293 \cdot 10^{-6}$ & $2.829 \cdot 10^{-6}$ & $7.435 \cdot 10^{-7}$ & $1.395 \cdot 10^{-7}$ \\
\hline Aliquat $336+i$-octanol & $(20+80)$ & $5.736 \cdot 10^{-8}$ & $4.928 \cdot 10^{-8}$ & $1.790 \cdot 10^{-8}$ & $3.360 \cdot 10^{-9}$ \\
\hline Aliquat $336+i$-octanol & $(40+60)$ & $3.319 \cdot 10^{-8}$ & $2.851 \cdot 10^{-8}$ & $9.099 \cdot 10^{-9}$ & $1.708 \cdot 10^{-9}$ \\
\hline Aliquat $336+i$-octanol & $(60+40)$ & $2.466 \cdot 10^{-8}$ & $2.118 \cdot 10^{-8}$ & $6.100 \cdot 10^{-9}$ & $1.145 \cdot 10^{-9}$ \\
\hline Aliquat $336+i$-octanol & $(80+20)$ & $2.019 \cdot 10^{-8}$ & $1.735 \cdot 10^{-8}$ & $4.587 \cdot 10^{-9}$ & $8.612 \cdot 10^{-10}$ \\
\hline Aliquat 336 & $(100)$ & $1.740 \cdot 10^{-8}$ & $1.495 \cdot 10^{-8}$ & $3.676 \cdot 10^{-9}$ & $6.901 \cdot 10^{-10}$ \\
\hline
\end{tabular}
highest viscosity. ${ }^{57}$

Table 3 -Diffusion coefficient $\left(D_{\text {LA-S }}\right)$ of levulinic acid in reactive solvent phase from the Wilke-Chang, Reddy-Doraiswamy, Scheibel, and Ratcliff equations at $298.15 \pm 1 \mathrm{~K}$ 
The feasibility of reactive extraction of LA with TBP, Aliquat 336, and TOA in $i$-octanol can be checked by calculating the solvent to feed ratio $[S / F]_{\min }$, and number of theoretical stages (NTS) proposed for the extraction of LA from water. The maximum extraction efficiency was found to be $80.05 \%$ with the distribution coefficient $\left(K_{\mathrm{D}}\right)$ of 4.01 using $40 \%$ TOA in $i$-octanol. The minimum separation was limited to $22 \%$ with $K_{\mathrm{D}}$ of 0.28 using $20 \%$ TBP in $i$-octanol.

The distribution coefficient can be used to calculate the $[S / F]_{\min }$ using the following equation: ${ }^{58}$

$$
\left[\frac{S}{F}\right]_{\min }=\frac{[\mathrm{LA}]_{\text {in }}-[\mathrm{LA}]_{\mathrm{W}}}{K_{\mathrm{D}}[\mathrm{LA}]_{\mathrm{in}}-[\mathrm{LA}]_{\mathrm{O}}}
$$

where $[\mathrm{LA}]_{\mathrm{in}},[\mathrm{LA}]_{\mathrm{w}}$, and $[\mathrm{LA}]_{\mathrm{O}}$ are the concentrations of LA in the feed, raffinate, and extract phases, respectively. As an empirical rule of thumb, actual solvent to feed ratio, $[S / F]_{\text {act }}$ is commonly set to 1.5 times the $[S / F]_{\min }$, because an extraction process is always associated with the finite number of extraction stages. The number of theoretical stages (NTS) in the extraction process of counter-current arrangement can be determined using the modified Kremser equation. It can be expressed as: ${ }^{59}$

$$
\mathrm{NTS}=\frac{\ln \left(\frac{[\mathrm{LA}]_{\mathrm{in}}-\frac{[\mathrm{LA}]_{\mathrm{O}}}{K_{\mathrm{D}}}}{[\mathrm{LA}]_{\mathrm{W}}-\frac{[\mathrm{LA}]_{\mathrm{O}}}{K_{\mathrm{D}}}}\right)\left(1-\frac{1}{E_{\mathrm{X}}}\right)+\frac{1}{E_{\mathrm{X}}}}{\ln E_{\mathrm{X}}}
$$

where $E_{\mathrm{X}}$ is calculated by:

$$
E_{\mathrm{X}}=K_{\mathrm{D}}\left[\frac{S}{F}\right]_{\text {act }}
$$

Table 4 describes the various values of NTS calculated at the nodes of maximum and minimum distribution coefficients among the studied points using TBP, Aliquat 336, and TOA in $i$-octanol. The NTS values of 2.10 and 0.81 were found using TBP in $i$-octanol, 2.41 and 0.78 were found for Aliquat 336 in $i$-octanol, and 2.80 and 1.45 for TOA in $i$-octanol at maximum and minimum nodes, respectively. The low values of NTS indicate that the mixer-settler is sufficient for the desired extraction of acid. The overall study suggests that around three stages are enough to achieve the sufficient separation of LA using TOA as extractant. The stages can be used in series to achieve higher separation of LA using TBP and Aliquat 336. The higher NTS leads to increased contact time between the solute and solvent phase, thus providing increased mass transfer in the solvent phase. Therefore, the flow rate of feed needs to be decreased to improve the separation of LA if TBP and Aliquat 336 are to be used as extractants.

\section{Conclusion}

The various extractants: TOA, TBP, and Aliquat 336 dissolved in $i$-octanol were employed for the extraction of LA from aqueous solution. The effect of various performance parameters was discussed. The separation efficiency of LA was found to decrease in the order of TOA $>$ Aliquat $336>$ TBP for all concentrations of extractants in $i$-octanol. The extreme extraction efficiency $(\eta)$ of $80.05 \%$ was observed with $40 \%$ TOA in $i$-octanol, whereas $68.48 \%$ and $74.60 \%$ was obtained with $100 \%$ of TBP and Aliquat 336, respectively. Thus, $40 \%$ TOA provided higher separation of LA as compared to pure TBP and Aliquat 336. The equilibrium complexation constant $\left(K_{\mathrm{E}}\right)$ and solvation number $(m)$ were evaluated based on the assumption of complex 1:1 acid-extractant formation in TBP and Aliquat 336 . In the case of TOA, it was evaluated based on 1:1 and 2:1 acid-extractant complex formation. The column design calculations were attempted and the number of three theoretical plates (NTS) was found necessary for TOA in $i$-octanol case. The data presented can be useful for the successful commercial implementation of reactive separation of levulinic acid.

Table 4 -Calculation of minimum solvent-to-feed ratio $(S / F)$ and number of theoretical stages (NTS) for the maximum and minimum separation of LA with initial concentration of $0.441 \mathrm{~mol} \mathrm{~kg}^{-1}$

\begin{tabular}{c|c|c|c|c|c|c}
\hline Extractants & Separation of LA & $\begin{array}{c}{[\mathrm{LA}]_{\text {in }}} \\
\left(\mathrm{mol} \mathrm{kg}^{-1}\right)\end{array}$ & $\begin{array}{c}{[\mathrm{LA}]_{\mathrm{W}}} \\
\left(\mathrm{mol} \mathrm{kg}^{-1}\right)\end{array}$ & $K_{\mathrm{D}}$ & $(S / F)_{\min }$ & NTS \\
\hline \multirow{2}{*}{ TBP } & Maximum & 0.441 & 0.139 & 2.173 & 0.316 & 2.10 \\
& Minimum & 0.441 & 0.344 & 0.282 & 0.112 & 0.81 \\
\multirow{3}{*}{ Aliquat 336 } & Maximum & 0.441 & 0.112 & 2.938 & 0.255 & 2.41 \\
& Minimum & 0.441 & 0.339 & 0.301 & 0.079 & 0.78 \\
& Maximum & 0.441 & 0.088 & 4.011 & 0.200 & 2.80 \\
& Minimum & 0.441 & 0.213 & 1.070 & 0.129 & 1.45 \\
\hline
\end{tabular}




\section{References}

1. Uslu, H., Kirbaşlar, S. I., Investigation of levulinic acid distribution from aqueous phase to organic phase with TOA extractant, Ind. Eng. Chem. Res. 47 (2008) 4598. doi: https://doi.org/10.1021/ie800103u

2. Andersson-Engels, S., Multi-colour fluorescence imaging in connection with photodynamic therapy of $\delta$-amino levulinic acid (ALA) sensitised skin malignancies, Bioimaging 3 (1995) 134.

doi: https://doi.org/10.1002/1361-6374(199509) 3:3\%3C134::AID-BIO4\%3E3.0.CO;2-1

3. Mthembu, L. D., Production of levulinic acid from sugarcane bagasse, Master thesis, Durban University of Technology, 2015.

4. Zhang, $J$., $W u, S$., Li, B., Zhang, $H$., Advances in the catalytic production of valuable levulinic acid derivatives, ChemCatChem. 4 (2012) 1230.

doi: https://doi.org/10.1002/cctc.201200113

5. Pasquale, G., Vázquez, P., Romanelli, G., Baronetti, G., Catalytic upgrading of levulinic acid to ethyl levulinate using reusable silica-included Wells-Dawson heteropolyacid as catalyst, Catal. Commun. 18 (2012) 115. doi: https://doi.org/10.1016/j.catcom.2011.12.004

6. Rackemann, D. W., Doherty, W. O., The conversion of lignocellulosics to levulinic acid, The conversion of lignocellulosics to levulinic acid, Biofuel. Bioprod. Biorefin. 5 (2011) 198. doi: https://doi.org/10.1002/bbb.267

7. Huber, G. W., Iborra, S., Corma, A., Synthesis of transportation fuels from biomass: Chemistry, catalysts, and engineering, Chem. Rev. 106 (2006) 4044. doi: https://doi.org/10.1021/cr068360d

8. URL: http://www.gfbiochemicals.com/products (22.3.2021.)

9. URL: https://blommabeauty.com/blogs/ingredients/levulinic-acid-sodium levulinate\#: :text=Levulinic\% $\%$ acid $\% 20$ is $\% 20 \mathrm{a} \% 20$ natural,from $\% 20$ regular $\% 20$ contact $\% 20$ and\%20use (22.3.2021.)

10. Kumar, A., Shende, D. Z., Wasewar, K. L., Separation of levulinic acid by reaction with tri-n-butylphosphate diluted in nontoxic solvents, J. Chem. Eng. Data 65 (2020) 3002. doi: https://doi.org/10.1021/acs.jced.0c00007

11. URL:https://www.thechemicalengineer.com/news/top-tenbio-based-chemicals-for-uk economic-growth (22.3.2021.)

12. Muranaka, Y., Suzuki, T., Sawanishi, H., Hasegawa, I., Mae, K., Effective production of levulinic acid from biomass through pretreatment using phosphoric acid, hydrochloric acid, or ionic liquid, Ind. Eng. Chem. Res. 53 (2014) 11611. doi: https://doi.org/10.1021/ie501811x

13. URL: https://www.nrel.gov/docs/fy04osti/35523. pdf (4.4.2021.)

14. URL: https://reportsanddata.com/report-detail/levulinic-acid-market (29.10.2021.)

15. Victor, A., Pulidindi, I. N., Gedanken, A., Levulinic acid production from Cicer arietinum, cotton, Pinus radiata and sugarcane bagasse, RSC. Adv. 4 (2014) 44706. doi: https://doi.org/10.1039/C4RA06246A

16. Yan, L., Yang, N., Pang, H., Liao, B., Production of levulinic acid from bagasse and paddy straw by liquefaction in the presence of hydrochloride acid, Clean (Weinh) 36 (2008) 158. doi: https://doi.org/10.1002/clen.200700100

17. Bevilaqua, D. B., Rambo, M. K., Rizzetti, T. M., Cardoso, A. L., Martins, A. F., Cleaner production: Levulinic acid from rice husks, J. Clean. Prod. 47 (2013) 96. doi: https://doi.org/10.1016/j.jclepro.2013.01.035
18. Chang, C., Cen, P., Ma, X., Levulinic acid production from wheat straw, Bioresour. Technol. 98 (2007) 1448. doi: https://doi.org/10.1016/j.biortech.2006.03.031

19. Alipour, S., Omidvarborna, H., High concentration levulinic acid production from corn stover, RSC. Adv. 6 (2016) 111616. doi: https://doi.org/10.1039/C6RA23768A

20. Jeong, H., Jang, S. K., Hong, C. Y., Kim, S. H., Lee, S. Y., Lee, S. M., Choi, I. G., Levulinic acid production by twostep acid-catalyzed treatment of Quercus mongolica using dilute sulfuric acid, Bioresour. Technol. 225 (2017) 183. doi: https://doi.org/10.1016/j.biortech.2016.11.063

21. Moyer, W. W., US. Patent Appl. 2,328, 20 Jan 1942.

22. Tiong, Y. W., Yap, C. L., Gan, S., Yap, W. S. P., Conversion of biomass and its derivatives to levulinic acid and levulinate esters via ionic liquids, Ind. Eng. Chem. Res. 57 (2018) 4749. doi: https://doi.org/10.1021/acs.iecr.8b00273

23. Kumar, A., Shende, D. Z., Wasewar, K. L., Production of levulinic acid: A promising building block material for pharmaceutical and food industry, Mater. Today Proceed. 29 (2020) 790. doi: https://doi.org/10.1016/j.matpr.2020.04.749

24. Kumar, A., Shende, D. Z., Wasewar, K. L., Recovery of levulinic acid in its production using agriculture waste residue, SSRN (2020) 3707323. doi: https://dx.doi.org/10.2139/ssrn.3707323

25. Uslu, $H$., Reactive extraction of levulinic acid using TPA in toluene solution: LSER modeling, kinetic and equilibrium studies, Separ. Sci. Technol. 43 (2008) 1535. doi: https://doi.org/10.1080/01496390801941216

26. Eda, S., Borra, A., Parthasarathy, R., Bankupalli, S., Bhargava, S., Thella, P. K., Recovery of levulinic acid by reactive extraction using tri-n-octylamine in methyl isobutyl ketone: Equilibrium and thermodynamic studies and optimization using Taguchi multivariate approach, Sep. Purif. Technol. 197 (2018) 314 doi: https://doi.org/10.1016/j.seppur.2018.01.014

27. Wasewar, K. L., Reactive extraction: An intensifying approach for carboxylic acid separation, Int. J. Chem. Eng. Appl. 3 (2012) 249. doi: https://doi.org/10.7763/IJCEA.2012.V3.195

28. Inyang, $V$., Lokhat, D., Reactive extraction of malic acid using trioctylamine in 1-decanol: Equilibrium studies by response surface methodology using Box Behnken optimization technique, Sci. Rep. 10 (2020) 1. doi: https://doi.org/10.1038/s41598-020-59273-z

29. Türk, F. N., Çehreli, S., Baylan, N., Reactive extraction of monocarboxylic acids (formic, acetic, and propionic) using tributyl phosphate in green solvents (cyclopentyl methyl ether and 2-methyltetrahydrofuran), J. Chem. Eng. Data 66 (2020) 130. doi: https://doi.org/10.1021/acs.jced.0c00486

30. Kumar, A., Shende, D., Wasewar, K., Central Composite Design approach for optimization of levulinic acid separation by reactive components, Ind. Eng. Chem. Res. 60 (2021) 13692

doi: https://doi.org/10.1021/acs.iecr.1c02589

31. Thakre, N., Prajapati, A. K., Mahapatra, S. P., Kumar, A., Khapre, A., Pal, D., Modeling and optimization of reactive extraction of citric acid, J. Chem. Eng. Data 61 (2016) 2614 doi: https://doi.org/10.1021/acs.jced.6b00274

32. Kaur, G., Elst, K., Development of reactive extraction systems for itaconic acid: A step towards in situ product recovery for itaconic acid fermentation, RSC Adv. 4 (2014) 45029. doi: https://doi.org/10.1039/C4RA06612J 
33. Baylan, N., Imidazolium-based ionic liquids for acrylic acid separation from water by bulk liquid membrane and extraction methods: A comparison study, J. Chem. Eng. Data $65(2020) 3121$.

doi: https://doi.org/10.1021/acs.jced.0c00137

34. Ayan, E., Baylan, N., Çehreli, S., Optimization of reactive extraction of propionic acid with ionic liquids using central composite design, Chem. Eng. Res. Des. 153 (2020) 666. doi: https://doi.org/10.1016/j.cherd.2019.11.015

35. Marti, M. E., Gurkan, T., Selective recovery of pyruvic acid from two and three acid aqueous solutions by reactive extraction, Sep. Purif. Technol. 156 (2015) 148. doi: https://doi.org/10.1016/j.seppur.2015.09.067

36. Inyang, $V$., Lokhat, D., Kinetic studies on propionic and malic acid reactive extraction using trioctylamine in 1-decanol, Chem. Pap. 74 (2020) 3597.

doi: https://doi.org/10.1007/s11696-020-01194-2

37. Omwene, P. I., Yagcioglu, M., Sarihan, Z. B. O., Karagun$d u z, A$., Keskinler, B., Recovery of succinic acid from whey fermentation broth by reactive extraction coupled with multistage processes, J. Environ. Chem. Eng. 8 (2020) 104216. doi: https://doi.org/10.1016/j.jece.2020.104216

38. Han, Y. H., Park, Y. L., Yang, S. Y., Jung, H. R., Joo, J. C., Song, B. K., Yang, Y. H., Selective extraction of glutaric acid from biological production systems using $n$-butanol, J. Ind. Eng. Chem. 82 (2020) 98. doi: https://doi.org/10.1016/j.jiec.2019.09.047

39. Taylor, J. R., An Introduction to Error Analysis: The Study of Uncertainties in Physical Measurements, $2^{\text {nd }}$ ed., University Science Books, Sausalito, California, 1997.

40. Keshav, A., Wasewar, K. L., Chand, S., Extraction of propionic acid using different extractants (tri- $n$-butylphosphate, tri- $n$-octylamine, and Aliquat 336), Ind. Eng. Chem. Res. 47 (2008) 6192 doi: https://doi.org/10.1021/ie800006r

41. Streng, W. H., Partition Coefficient. In: Characterization of Compounds in Solution. Springer, Boston, MA (2001) 60. doi: https://doi.org/10.1007/978-1-4615-1345-2_5

42. Bízek, V., Horáček, J., Koušová, M., Amine extraction of citric acid: Effect of diluent. Chem Eng. Sci. 48 (1993) 1447. doi: https://doi.org/10.1016/0009-2509(93)80051-Q

43. Wasewar, K. L., Yawalkar, A. A., Moulijn, J. A., Pangarkar, $V$. G., Fermentation of glucose to lactic acid coupled with reactive extraction: A review, Ind. Eng. Chem. Res. 43 (2004) 5969. doi: https://doi.org/10.1021/ie049963n

44. Keshav, A., Wasewar, K. L., Chand, S., Reactive extraction of propionic acid using tri- $n$-octylamine, tri- $n$-butyl phosphate and Aliquat 336 in sunflower oil as diluent, J. Chem. Tech. Biotech. 84 (2009) 484. doi: https://doi.org/10.1002/jctb.2066

45. Kertes, A. S., King, C. J., Extraction chemistry of fermentation product carboxylic acids, Biotechnol. Bioeng. 28 (1986) 269.

doi: https://doi.org/10.1002/bit.260280217
46. Tamada, J. A., Kertes, A. S., King, C. J., Extraction of carboxylic acids with amine extractants. 1. Equilibria and law of mass action modeling, Ind. Eng. Chem. Res. 29 (1990) 1319 . doi: https://doi.org/10.1021/ie00103a035

47. Keshav, A., Norge, P., Wasewar, K. L., Reactive extraction of citric acid using tri-n-octylamine in nontoxic natural diluents: Part 1 - equilibrium studies from aqueous solutions. Appl. Biochem. Biotechnol. 167 (2012) 197.

48. Tamada, J. A., Kertes, A. S., King, C. J., Extraction of carboxylic acids with amine extractants. 2 . Chemical interactions and interpretation of data, Ind. Eng. Chem. Res. 29 (1990) 1327. doi: https://doi.org/10.1021/ie00103a036

49. URL:https://chem.libretexts.org/Bookshelves/Physical and Theoretical_Chemistry_Textbook_Maps/Supplemental_Modules_(Physical_and_Theoretical_Chemistry)/Equilibria/Chemical_Equilibria/The_Equilibrium_Constant (03.12.2021)

50. Stenström, S., Dalene, M., Skarping, G., The solubility of tri- $n$-octylamine in water and phosphoric acid solutions, Anal. Chim. Acta 177 (1985) 279.

51. Datta, D., Kumar, S., Uslu, H., Status of the reactive extraction as a method of separation, J. Chem. 2015 (2015) 853789. doi: https://doi.org/10.1155/2015/853789

52. Umesi, N. O., Danner, R. P., Predicting diffusion coefficients in nonpolar solvents, Ind. Eng. Chem. Proc. Des. Dev. 20 (1981) 662. doi: https://doi.org/10.1021/i200015a014

53. Reddy, K. A., Doraiswamy, L. K., Industrial and Engineering Chemistry Fundamentals, 77 (1967) 530. doi: https://doi.org/10.1021/i160021a012

54. Wilke, C. R., Chang, P., Correlation of diffusion coefficients in dilute solutions, AIChE J. 1 (1955) 264. doi: https://doi.org/10.1002/aic.690010222

55. Scheibel, E. G., Correspondence. Liquid diffusivities. Viscosity of gases, Ind. Eng. Chem. 46 (1954) 2007. doi: https://doi.org/10.1021/ie50537a062

56. Li, J., Carr, P. W., Accuracy of empirical correlations for estimating diffusion coefficients in aqueous organic mixtures, Anal. Chem. 69 (1997) 2530. doi: https://doi.org/10.1021/ac961005a

57. Kojima, T., Fukutomi, H., Extraction equilibria of hydrochloric acid by trioctylamine in low-polar organic solvents. Bull. Chem. Soc. Jap. 60 (1987) 1309. doi: https://doi.org/10.1246/bcsj.60.1309

58. Seader, J. D., Henley, E. J., Roper, D. K., Separation Process Principles, Wiley, New York 1998.

59. Goring, G. E., A modified Kremser equation for stagewise countercurrent processes, Sep. Sci. 5 (1970) 113. doi: https://doi.org/10.1080/00372367008057953 